\title{
COMPARATIVE STUDIES ON THE ACID PROTEINASE ACTIVITIES IN THE digestive fluids of NePENTHES, CEPHALOtUs, DionaEA, ANd Drosera
}

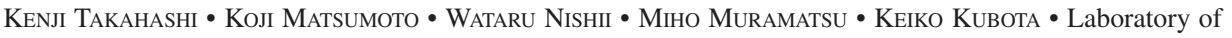 \\ Molecular Biochemistry, School of Life Sciences, Tokyo University of Pharmacy and Life Sciences \\ -1432-1 Horinouchi, Hachioji • Tokyo 192-0392 • Japan
}

ChIAKI SHIBATA • Department of Biology, The Nippon Dental University • Chiyoda-ku • Tokyo 102-8159 • Japan

Senareth B.P. Athauda - Department of Biochemistry • Faculty of Medicine • University of Peradeniya

- Peradeniya $\bullet$ Sri Lanka

Keywords: chemistry: Nepenthes, Cephalotus, Dionaea, Drosera

Received: 10 December 2007

Introduction

There are various kinds of carnivorous plants in nature, and most of them excrete acidic digestive fluids which contain digestive enzymes, especially acidic proteinases, to digest trapped insects and other prey for nutrition (Juniper et al. 1989). Previous inhibitor studies (Lobareva et al. 1973; Takahashi et al. 1974; Tökés et al. 1974) indicated that the acid proteinase nepenthesin from Nepenthes belongs to the aspartic proteinase family. Recently, we purified two nepenthesins from the digestive fluid of $N$. distillatoria, investigated their molecular and enzymatic properties, and elucidated their primary structures by cDNA cloning of nepenthesins from N. gracilis (Athauda et al. 1998, 2002, 2004; Takahashi et al. 2005). The peptide bond cleavage specificity of nepenthesin was investigated using $N$. alata pitcher fluid (Ann et al. 2002), partially purified nepenthesin from a mixture of several Nepenthes species (Amagase et al. 1969) and from N. macfarlanei (Tökés et al. 1974), and fully purified nepenthesin from N. distillatoria (Athauda et al. 2004; Takahashi et al. 2005). In addition, some enzymatic properties of the acid proteinase activities in the crude digestive fluids of Nepenthes sp. (Lüttge, 1964) and Dionaea muscipula (Scala et al. 1969; Robins \& Juniper 1980) and a partially purified acid proteinase from Drosera peltata (Amagase et al. 1972a, 1972b) were reported. Except for these studies, however, not many studies have been performed on the enzymatic properties of these acid proteinases. Therefore, further studies are necessary to understand more extensively the nature of the acid proteinases in the digestive fluids of carnivorous plants. Since the digestion takes place in the crude digestive fluid, it is thought to be important to characterize the acid proteinase activity as a whole as well as to purify and characterize the individual proteinases. Thus, we have investigated in the present study some enzymatic properties of the acid proteinase activities in the crude digestive fluids of typical carnivorous plants including two pitcher plants, Nepenthes alata and Cephalotus follicularis, one plant with a snap-trap, Dionaea muscipula (Venus flytrap), and one plant with a mucilage trap, Drosera capensis (sundew), in a comparative manner. The results demonstrated significant differences among them, presumably reflecting the phylogenic diversity of these carnivorous plants.

\section{Materials and Methods}

The crude digestive fluids of Nepenthes alata and Cephalotus follicularis were collected in the Daishoen plantation (Numazu). Dionea muscipula and Drosera capensis were obtained from the Daishoen plantation and grown at the botanical garden of Tokyo University of Pharmacy and Life Sciences to obtain their digestive fluids. The digestive fluid of Dionaea was collected 3 to 4 days after giving a piece (about 3-5 $\times 3-5 \times 2-3 \mathrm{~mm}$ ) of boiled egg white, thereby inducing closure of the two lobes by stimulating the trigger hairs. The digestive fluid of Drosera was collected by soaking ten leaves successively (1 leaf for $1 \mathrm{~min}$ at a time) in $800 \mu \mathrm{l}$ of $0.1 \mathrm{M}$ sodium acetate buffer, $\mathrm{pH} 4.0$, in a test tube to wash out the digestive fluid through up-and-down strokes. The $\mathrm{pH}$ was determined using a glass electrode in a Horiba $\mathrm{pH}$-meter. The samples were kept frozen at $-20^{\circ} \mathrm{C}$ 
until use. Porcine pepsin A, bovine hemoglobin, the B chain of oxidized bovine insulin and leucyl-4-methylcoumaryl-7-amide (Leu-MCA) and arginyl-4-methylcoumaryl-7-amide (Arg-MCA) were obtained from Sigma and pepstatin A from Peptide Institute, Osaka. Other reagents used were of analytical grade.

The proteinase activities of the digestive fluids of Nepenthes, Cephalotus, and Dionaea were determined with bovine hemoglobin as a substrate at pH 2.0 as described (Athauda et al. 1989), and expressed in pepsin equivalent using porcine pepsin A (Sigma) as a standard. The proteinase activity of the digestive fluid of Drosera capensis in the hemoglobin assay was markedly low as compared with those of the other three. Therefore oxidized insulin B chain was used as a substrate and the digestion products were analyzed by HPLC. The assay mixture was composed of 1-40 $\mu$ l of enzyme solution, $10 \mu \mathrm{l}$ of oxidized insulin B chain $(1 \mathrm{mg} / \mathrm{ml})$, $50 \mu \mathrm{l}$ of $0.1 \mathrm{M}$ sodium acetate buffer, $\mathrm{pH} 4.0$, an appropriate volume (0-39 $\mu \mathrm{l})$ of water in a total volume of $100 \mu \mathrm{l}$, and the digestion was performed at $37^{\circ} \mathrm{C}$ for $1 \mathrm{~h}$ and terminated by the addition of $100 \mu \mathrm{l}$ of $0.5 \mathrm{M}$ $\mathrm{H}_{3} \mathrm{BO}_{3}-\mathrm{KCl} / \mathrm{NaOH}$ buffer, $\mathrm{pH} 9.8$. A $100-\mu 1$ aliquot from the reaction mixture was analyzed by reverse-phase HPLC using a Shimadzu LC10A system on a Tosoh ODS-120T column $(4.6 \times 250 \mathrm{~mm})$ eluted with an acetonitrile gradient ( 0 to $60 \%$ ) in $0.1 \%$ trifluoroacetic acid at a flow rate of $1.0 \mathrm{ml} / \mathrm{min}$ and monitored at $215 \mathrm{~nm}$. The activity was estimated from the decrease in the amount of the substrate, and expressed in pepsin equivalent determined using porcine pepsin $\mathrm{A}$ as a standard under the same assay conditions at $\mathrm{pH}$ 4.0.

Aminopeptidase activities were determined with Leu-MCA and Arg-MCA as substrates. The assay mixture contained $5 \mu \mathrm{l}$ (Nepenthes), $200 \mu \mathrm{l}$ (Cephalotus), or $10 \mu \mathrm{l}$ (Dionaea) of enzyme solution, $5 \mu \mathrm{l}$ of $10 \mathrm{mM}$ substrate in dimethylsulfoxide, $310 \mu \mathrm{l}$ of $0.1 \mathrm{M}$ citric acid- $\mathrm{Na}_{2} \mathrm{HPO}_{4}$ buffer, $\mathrm{pH}$ 3.0-6.0, and an appropriate volume $(0-195 \mu \mathrm{l})$ of water in a total volume of $515 \mu \mathrm{l}$. The digestion was performed at $37^{\circ} \mathrm{C}$ for $30 \mathrm{~min}$ and stopped by the addition of $2.5 \mathrm{ml}$ of $5 \%$ trichloroacetic acid. The amount of 7-amino-4-methylcoumarin liberated was measured in a Hitachi spectrofluorometer with excitation at $380 \mathrm{~nm}$ and emission at $460 \mathrm{~nm}$.

Native electrophoresis followed by activity staining was performed as follows. An appropriate portion $(20 \mu 1)$ of each pitcher fluid was submitted to native polyacrylamide gel electrophoresis using $10 \%$ acrylamide gel and Tris-glycine buffer, $\mathrm{pH} 8.7$, and then proteinase activity was examined by activity staining with hemoglobin as a substrate at pH 1.7 essentially as described (Furihata et al. 1972).

To investigate the substrate specificity, oxidized insulin B chain was used as a substrate. The reaction mixture contained $10 \mu \mathrm{l}$ (Nepenthes), $40 \mu \mathrm{l}$ (Cephalotus), or $3 \mu \mathrm{l}$ (Dionaea) of the digestive fluid containing about 1 pmol enzyme as porcine pepsin equivalent, $10 \mu \mathrm{l}$ of oxidized insulin B chain $(1 \mathrm{mg} / \mathrm{ml}), 50 \mu \mathrm{of}$ $0.1 \mathrm{~m}$ sodium formate buffer, $\mathrm{pH} 3.0$, and an appropriate volume $(0-37 \mu \mathrm{l})$ of water in a total volume of $100 \mu \mathrm{l}$. The digestion was performed at $37^{\circ} \mathrm{C}$ for $3 \mathrm{~h}$, and the resulting peptides were analyzed using an HPLC apparatus (1100 series, Agilent Technology) with a TSKgel ODS-120T column $(2.2 \times 150 \mathrm{~mm})$ connected to an LC $^{\mathrm{TM}}$-DUO mass spectrometer (ThermoQuest). Amino acid sequences of the peptides produced were determined from the mass spectra of the original and fragmented ions by using Xcalibur Bioworks 1.0 software installed in the apparatus as described (Nishii et al. 2002).

\section{Results and Discussion}

The collected fluid samples of Nepenthes alata, Cephalotus follicularis, and Dionaea muscipula had a $\mathrm{pH}$ of 2.9, 2.9, and 3.9, respectively, and were shown to contain approximately $10 \mathrm{pmol}, 2 \mathrm{pmol}$, and $40 \mathrm{pmol}$, respectively, of acid proteinase in pepsin equivalent per $100 \mu \mathrm{l}$ as determined with hemoglobin as a substrate. On the other hand, the digestive fluid of Drosera capensis had a pH of about 2.5, and the washate of ten leaves with $800 \mu$ lof the $\mathrm{pH} 4.0$ buffer contained approximately $100 \mathrm{pmol}$ of acid proteinase in pepsin equivalent per $100 \mu l$ as determined with oxidized insulin B chain as a substrate.

Figure 1 shows the activity staining after native polyacrylamide gel electrophoresis (PAGE) of the crude digestive fluids. Two broad bands are seen for the Nepenthes sample; the major, slow-moving band should correspond to nepenthesin I and the minor, fast-moving band to nepenthesin II. These broad bands may contain more then one acid proteinase isozyme as shown for nepenthesins I and II from $N$. gracilis and $N$. distillatoria (Athauda et al. 2004; Takahashi et al. 2005). The Dionaea sample gave a single broad band moving almost in parallel with nepenthesin I, but the band corresponding to nepenthesin II was hardly seen. The major band may contain more than one acid proteinase component. Indeed, it was reported previously that two major bands were detected on native PAGE of the digestive fluid of Dionaea muscipula (Robins \& Juniper 1980). In the case of Cephalotus, there are two bands comparable with the nepenthesin bands, but the major band corresponding to nepenthesin I had higher mobility toward cathode. Thus, the electrophoretic patterns are similar but not identical among the three samples. The analysis of the Drosera sample gave no clear band presumably due to the low sensitivity of the enzyme toward hemoglobin (data not shown). 
Figure 2 shows the $\mathrm{pH}$ profiles of the enzymatic activities. Both the Nepenthes and Cephalotus samples had the $\mathrm{pH}$ optimum at around 2.5, whereas the Dionaea and Drosera samples showed the $\mathrm{pH}$ optimum at 3.0 and 3.5 , respectively. The result with the Nepenthes sample is similar to the $\mathrm{pH}$ profiles of nepenthesins I and II from $N$. distillatoria having an optimum at $\mathrm{pH} 2.6$ and that of the crude fluid from $N$. distillatoria with an optimum at $\mathrm{pH} 2.8$ (Athauda et al. 2004; Takahashi et al. 2005). As compared with the $\mathrm{pH}$ profile of the Cephalotus sample, those of the other three had broader $\mathrm{pH}$ profiles, which might mean that they are composed of more than one enzyme component with fairly different $\mathrm{pH}$ optima. As for the Dionaea digestive fluid, the $\mathrm{pH}$-activity profile with casein as a substrate was reported to show two peaks at $\mathrm{pH} 4.0$ and 5.0 (Robins \& Juniper 1980) or one sharp peak at pH 5.3 (Scala et al. 1969). Several pH optima (Chandler \& Anderson 1976) or an irregular $\mathrm{pH}$ profile (Clancy \& Coffey 1977) with casein as a substrate were reported for the digestive fluids of Drosera species. The reason for the differences between the present results and those reported previously is not clear at present, but might be at least partly due to the difference in the assay conditions, especially in the substrate used.

The temperature dependence of activity of each sample is shown in Figure 3a. The Nepenthes sample showed a temperature-activity profile with a maximum at about $57^{\circ} \mathrm{C}$. This is similar to that of nepenthesin I from $N$. distillatoria which has a maximum at $55^{\circ} \mathrm{C}$, but the maximum temperature was higher than that of the crude fluid from $N$. distillatoria with a maximum at $50^{\circ} \mathrm{C}$ (Athauda et al. 2004; Takahashi et al. 2005). The results are roughly similar to that reported for the digestive fluid of $N$. khasiana (Lüttge 1964). On the other hand, the Cephalotus, Dionaea, and Drosera samples showed a temperature-activity profile with a maximum at $47^{\circ} \mathrm{C}$, $47^{\circ} \mathrm{C}$, and $42^{\circ} \mathrm{C}$, respectively, which are apparently similar to that of nepenthesin II from $N$. distillatoria (Athauda et al. 2004; Takahashi et al. 2005). The profile of the Dionaea sample has a shoulder at around $60^{\circ} \mathrm{C}$, which might indicate the presence of more than one component with fairly different temperature dependence of activity.

The results of temperature-stability experiments are shown in Figure 3b, in which each crude sample was incubated at different temperatures for $1 \mathrm{~h}$, then the remaining activity was determined. As for the Nepenthes sample, the activity was stable up to around $53^{\circ} \mathrm{C}$, then started to decrease and was lost completely at around $80^{\circ} \mathrm{C}$. This result was similar to those obtained with nepenthesin I and the crude fluid from N. distillatoria (Athauda et al. 2004; Takahashi et al. 2005). A similar result was obtained with the

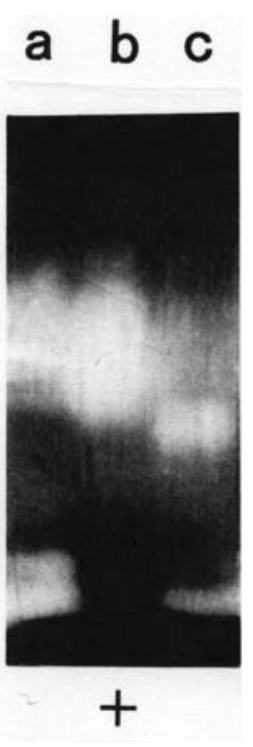

Figure 1:

Native polyacrylamide gel electrophoresis with proteinase activity staining of the digestive fluids of carnivorous plants. (a) Nepenthes alata, (b) Dionaea muscipula, (c) Cephalotus follicularis.

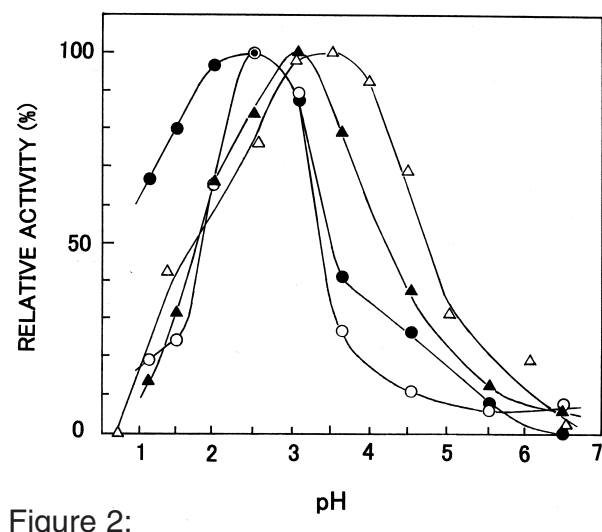

$\mathrm{pH}$ dependence of the proteinase activities of the digestive fluids of carnivorous plants. Closed circle, Nepenthes alata; open circle, Cephalotus follicularis; closed triangle, Dionaea muscipula; open triangle, Drosera capensis. The same symbols are used in Figures 3-5. Buffers used were $0.1 \mathrm{M} \mathrm{HCl} / \mathrm{KCl}$ buffers ( $\mathrm{pH} 1.1$ to 2.0) and $0.1 \mathrm{M}$ citric $\mathrm{acid} / \mathrm{Na}_{2} \mathrm{HPO}_{4}$ buffers ( $\mathrm{pH} 2.5$ to 6.5 ) except for Drosera for which $0.1 \mathrm{M} \mathrm{HCl} / \mathrm{KCl}$ buffers $(\mathrm{pH} 0.7$ to 1.4$), 0.1 \mathrm{M}$ glycine $/ \mathrm{HCl}$ buffers $(\mathrm{pH} 2.6$ to 3.5$), 0.1 \mathrm{M}$ potassium acetate $/ \mathrm{HCl}$ buffers $(\mathrm{pH} 4.0$ to 5.4$)$ and $0.1 \mathrm{M}$ $\mathrm{KH}_{2} \mathrm{PO}_{4} / \mathrm{NaOH}$ buffers (pH 6.1 to 6.6 ) were used. 


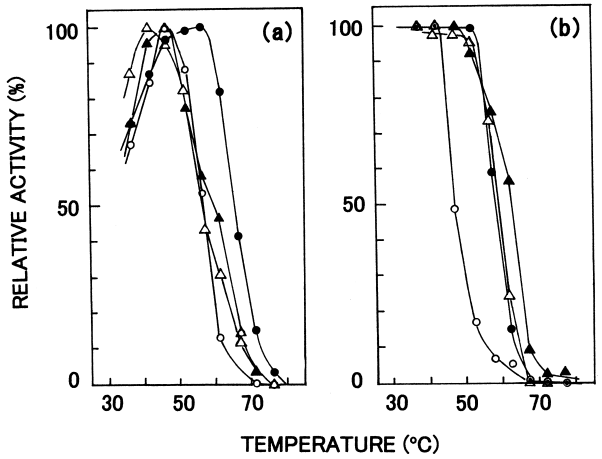

Figure 3:

Effects of temperature on the proteinase activities and stabilities of the digestive fluids of carnivorous plants. (a) The activity was measured at various temperatures at pH 2.0 except for the Drosera sample which was assayed at $\mathrm{pH}$ 4.0. (b) Each sample was incubated at various temperatures and $\mathrm{pH} 2.9$ (Nepenthes and Cephalotus), 3.9 (Dionaea), or 4.0 (Drosera) for $1 \mathrm{~h}$ at an enzyme concentration of approximately 5-10 pmol pepsin equivalents per $200 \mu \mathrm{l}$ and then assayed as above.

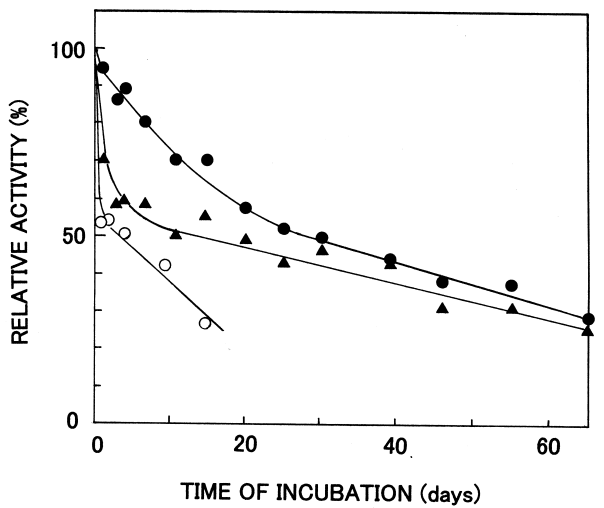

Figure 4:

Stabilities of the proteinase activities of the digestive fluids of carnivorous plants on long incubation. The activity was measured at $37^{\circ} \mathrm{C}$ after incubation of each sample for various periods at $37^{\circ} \mathrm{C}$ and $\mathrm{pH} 2.9$ (Nepenthes and Cephalotus) or 3.9 (Dionaea) at an enzyme concentration of approximately 5-10 pmol pepsin equivalents/200 $\mu \mathrm{l}$. The experiment with Drosera was not performed.
Drosera sample. On the other hand, the activity of the Cephalotus sample was less stable. It was stable up to $42^{\circ} \mathrm{C}$, where it started to decrease to zero at around $70^{\circ} \mathrm{C}$. Interestingly, the Dionaea sample was apparently more stable than the Nepenthes sample at above $55^{\circ} \mathrm{C}$. Thus, the $\mathrm{Tm}$ values were approximately $63^{\circ} \mathrm{C}$, $59^{\circ} \mathrm{C}, 58^{\circ} \mathrm{C}$, and $47^{\circ} \mathrm{C}$, respectively, for the Dionaea, Drosera, Nepenthes, and Cephalotus samples. The temperature-stability profile of the Dionaea sample was different from those of the other three. The activity was stable at around $50^{\circ} \mathrm{C}$, but above this temperature the inactivation appeared to proceed in two steps, suggesting the presence of at least two enzyme components different in heat stability. These results are consistent with the temperature dependences of the activities shown in Figure 3a.

Figure 4 shows the changes of the acid proteinase activities upon longer incubation at $37^{\circ} \mathrm{C}$. The activity of the Nepenthes sample decreased only very slowly on longer incubation; about $60 \%$ and $30 \%$ of the original activity were still retained after 30 days and 65 days of incubation, respectively. Thus, the activity of the crude digestive fluid of N. alata is considerably stable under the conditions used. However, under similar conditions, that of $N$. distillatoria retained nearly full activity after 30 days of incubation (Athauda et al. 2004; Takahashi et al. 2005). This difference might be due to the difference in the Nepenthes species used and/or the difference in the experimental conditions. In contrast to the Nepenthes sample, the activity of the Cephalotus sample was rather unstable; nearly $50 \%$ and $70 \%$ of the original activity were lost in $1 \mathrm{~h}$ and $15 \mathrm{~h}$, respectively. On the other hand, the Dionaea sample appeared to be considerably more stable than the Cephalotus sample, but somewhat less stable than the Nepenthes sample in the early phase of incubation; about $40 \%$ and $25 \%$ of the original activity were lost in $3 \mathrm{~h}$ and $65 \mathrm{~h}$, respectively. As can be seen from Figure 4, the profiles of the activity change of both Cephalotus and Dionaea samples appeared to be biphasic. This suggests that each of these samples contains a relatively unstable component and a more stable component. The latter component in Dionaea appears to be comparable in stability with the Nepenthes sample. The experiment with the Drosera sample has not yet been performed.

The effects of pepstatin A on the activity of each sample are shown in Figure 5. Under the conditions used, the activities of all samples appeared to be nearly half lost in the initial phase at a low pepstatin concentration (up to about $1 \mu \mathrm{M}$ ). At higher concentration of pepstatin, the Nepenthes and Cephalotus samples were inhibited further, but more weakly, and nearly complete inhibition occurred with $120 \mu \mathrm{M}$ of the inhibitor. On the other hand, the activity of the 
Dionaea sample was not inhibited completely; the activity was half inhibited at a low concentration of pepstatin A, but the remaining about $50 \%$ of the activity was almost insensitive to pepstatin A and remained uninhibited in the presence of $100 \mu \mathrm{M}$ inhibitor. In contrast, the Drosera sample was inhibited completely at a pepstatin concentration of $5 \mu \mathrm{M}$.

These results indicate the following. First, the Nepenthes and Cephalotus samples each may contain two kinds of enzymes with a higher and a lower affinity to pepstatin. Indeed, nepenthesins I and II of $N$. distillatoria have been shown to have different affinity to pepstatin (Athauda et al. 2004; Takahashi et al. 2005). Second, the Dionaea sample may contain a pepstatin-insensitive acid proteinase in addition to the nepenthesin-like pepstatin-sensitive acid proteinase. This pepstatin-insensitive enzyme has not yet been identified, but might be similar to glutamic peptidases such as aspergilloglutamic peptidase (Huang et al. 2000; Yabuki et al. 2004; Sasaki et al. 2004) and scytallidoglutamic peptidase (Fujinaga et al. 2004; Kataoka et al. 2005) or serine-carboxyl peptidases such as physarolisin (Nishii et al. 2003a, 2003b) and pseudomonalisin (Wlodawer et al. 2001), each of which is known to be insensitive to pepstatin but has an acidic $\mathrm{pH}$ optimum. To our knowledge, such an enzyme as a glutamic peptidase or serine-carboxyl peptidase has not been found so far in plants. The occurrence of at least two different types of acid proteinases is consistent with the biphasic character of the Dionaea proteinase activity observed already. The pepstatin-insensitive activity in the Dionaea sample appeared to be less stable than the pepstatin-sensitive activity when the enzyme sample was stored at $4^{\circ} \mathrm{C}$. In contrast to the present results, the acid proteinase activity in the Dionaea digestive fluid was previously reported to be insensitive to pepstatin (Robins \& Juniper 1980). The reason for this difference is not certain at present, but might partly be due to the occurrence of two different types of acid proteinases. Third, the Drosera sample may contain only acid proteinases with a relatively higher pepstatin affinity.

The peptide bond cleavage specificities of the acid proteinases in the Nepenthes, Cephalotus, and Dionaea samples as examined with oxidized insulin B chain as a substrate are shown in Figures 6 through 8 . In the Nepenthes sample, the major cleavages occurred at $\mathrm{Leu}^{15}-\mathrm{Tyr}^{16}$ and $\mathrm{Phe}^{24}-\mathrm{Phe}^{25}$, and moderate cleavages at $\mathrm{Glu}^{13}-\mathrm{Ala}^{14}, \mathrm{Ala}^{14}-\mathrm{Leu}^{15}, \mathrm{Tyr}^{16}-\mathrm{Leu}^{17}$, and $\mathrm{Tyr}^{26}-\mathrm{Thr}^{27}$. These results are roughly similar to those reported previously for the crude digestive fluid of N. alata (Ann et al. 2002) and the purified nepenthesin I from N. distillatoria (Athauda et al. 2004; Takahashi et al. 2005). In the latter case, Leu-Cys(ox) ${ }^{7}$ bond was cleaved to a significant extent, which might be due to species or isozymic difference. In the Cephalotus sample, the major cleavages occurred at $\mathrm{Leu}^{15}-\mathrm{Tyr}^{16}, \mathrm{Phe}^{24}-\mathrm{Phe}^{25}$, and $\mathrm{Lys}^{29}-\mathrm{Ala}^{30}$, and moderate cleavages at Glu ${ }^{13}-\mathrm{Ala}^{14}$ and $\mathrm{Ala}^{14}$ Leu $^{15}$. In the case of the Dionaea sample, the major cleavages occurred at Glu13-Ala14, Leu15-Tyr16, and $\mathrm{Phe}^{24}-\mathrm{Phe}^{25}$, and moderate cleavages at $\mathrm{Ala}^{14}-\mathrm{Leu}^{15}, \mathrm{Tyr}^{16}-\mathrm{Leu}^{17}, \mathrm{Gly}^{23}-\mathrm{Phe}^{24}$, and $\mathrm{Lys}^{29}-\mathrm{Ala}^{30}$. Thus, the major cleavages at $\mathrm{Leu}^{15}-\mathrm{Tyr}^{16}$ and $\mathrm{Phe}^{24}-\mathrm{Phe}^{25}$ were common, but the other cleavage sites varied significantly among the three samples. Especially, the Cephalotus and Dionaea samples differ from the Nepenthes sample in that $\mathrm{Lys}^{29}-\mathrm{Ala}^{30}$ and $\mathrm{Glu}^{13}-\mathrm{Ala}^{14}$, respectively, are also the major cleavage sites. These differences should reflect the difference in the cleavage specificity of the enzyme components in each sample.

Aminopeptidase activities in the acidic $\mathrm{pH}$ range were determined using Leu-MCA and ArgMCA as substrates. Neither activity was detected with Nepenthes and Cephalotus in the $\mathrm{pH}$ range of 3-6 and 3-5, respectively. As for Dionaea, a trace activity toward Leu-MCA was detected but no activity toward Arg-MCA in the $\mathrm{pH}$ range of 3-6. Therefore, practically no aminopeptidase action is assumed to be involved in the cleavages of oxidized insulin B chain observed in the present study. On the other hand, the activities of carboxypeptidases were not analyzed in the present study; the possibility for the action of a carboxypeptidase(s) cannot be completely excluded, however, considering the reports of the occurrence of carboxypeptidase in the digestive fluids of $N$. alata (Ann et al. 2002) and Dionaea (Robins \& Juniper 1980).

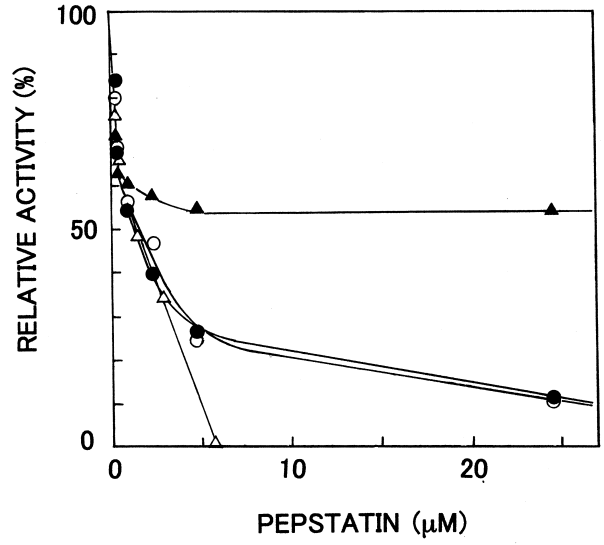

Figure 5:

Effects of pepstatin $A$ on the proteinase activities of the digestive fluids of carnivorous plants. The enzyme concentrations used were approximately 10-20 nM pepsin equivalents except for Drosera (400 nM), and the concentration of pepstatin was varied from 0 to $120 \mu \mathrm{M}$. 
In the present study, the hemoglobin-digestion method was not so useful for the assay of the Drosera capensis acid proteinase activity; instead, the oxidized insulin B chain was useful as a substrate for the assay as coupled with HPLC. Similar results were also obtained with $D$. filiformis. This may be due mainly to the difference in the substrate specificity of Drosera sp. from that of other carnivorous plants and remains to be clarified in a future study. During the course of the present studies, we have also examined the acid proteinase activities of the digestive fluids of some other carnivorous plants. So far, the digestive fluids of Drosophyllum

Figure 6: Cleavage specificity of the acid proteinase activity of the digestive fluid of Nepenthes alata on oxidized insulin B chain. (a) The chromatogram shows the HPLC pattern of the hydrolysis products. (b) The amino acid sequence of oxidized insulin B chain is given in the one-letter notation. $\mathrm{C}^{*}$, cysteic acid. Large, medium, and small closed arrowheads indicate the major, medium, and minor cleavages, respectively, and small open arrowhead, trace cleavage. The number for each peptide stands for the peak number, and that in parenthesis an approximate value for the relative yield of each peptide. The relative yield was calculated by dividing the peak height by the number of the peptide bonds, assuming the extent at the maximum cleavage site to be $100 \%$.

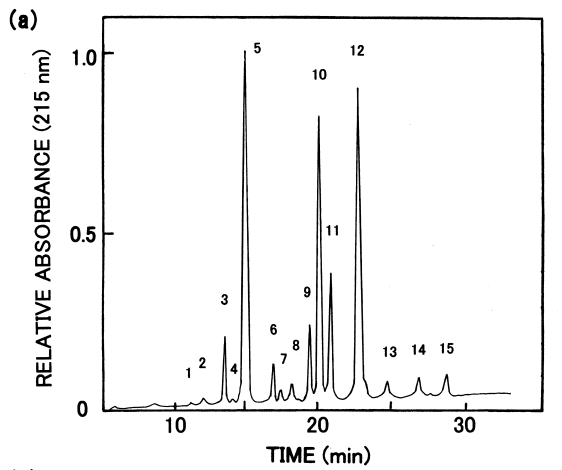

(b)

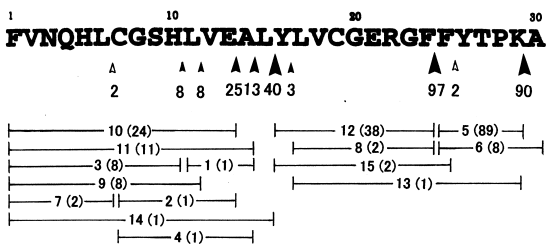

Figure 7: Cleavage specificity of the acid proteinase activity of the digestive fluid of Cephalotus follicularis on oxidized insulin B chain. The conditions are the same as those described in the legend to Figure 6.

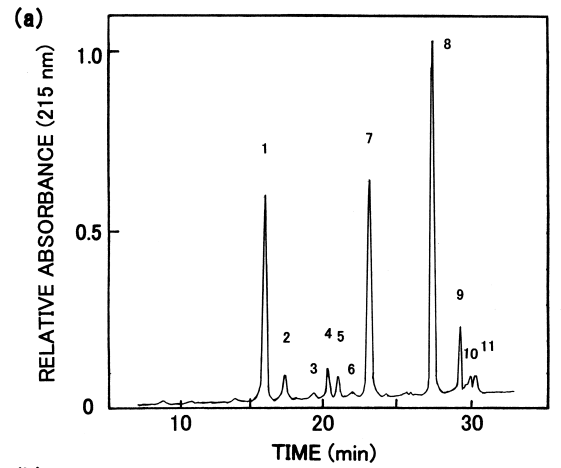

(b)

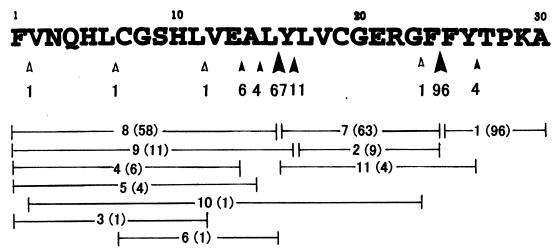

(a)

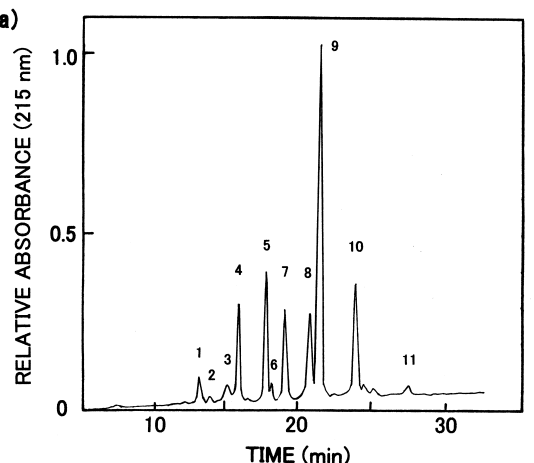

(b)

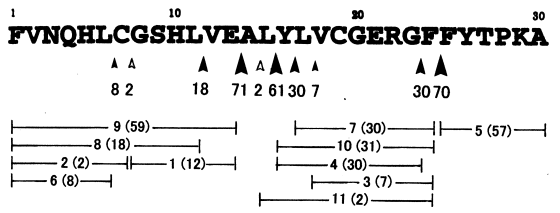

Figure 8: Cleavage specificity of the acid proteinase activity of the digestive fluid of Dionaea muscipula on oxidized insulin B chain. The conditions are the same as those described in the legend to Figure 6. 
lusitanicum and Byblis liniflora showed high activity toward both hemoglobin and oxidized insulin B chain, whereas that of Sarracenia purpurea failed to give any activity toward hemoglobin. Further extensive studies along this line, as well as purification and characterization of individual enzymes, including many more carnivorous plants, are necessary for deeper understanding of the biochemistry and physiology of the acid proteinases in the digestive fluids of carnivorous plants.

Acknowledgments: This study was supported in part by grants-in-aid for scientific research from the Japan Society for the Promotion of Science.

\section{References}

Amagase, S., Mori, M., and Nakayama, S. 1972a. Digestive enzymes in insectivorous plants. IV. Enzymatic digestion of insects by Nepenthes secretion and Drosera peltata extract; proteolytic and chitinolytic activities. J. Biochem. 72: 765-767.

Amagase, S., Mori, M., and Nakayama, S. 1972b. Digestive enzymes in insectivorous plants. III. Acid proteases in the genus Nepenthes and Drosera peltata. J. Biochem. 72: 73-81.

Amagase, S., Nakayama, S., and Tsugita, A. 1969. Acid protease in Nepenthes: II. Study on the specificity of nepenthesin. J. Biochem. 66: 431-439.

Ann, C.-L., Takekawa, S., Okazawa, A., Fukusaki, E., and Kobayashi, A. 2002. Degradation of a peptide in pitcher fluid of the carnivorous plant Nepenthes alata Blanco. Planta 215: 472-477.

Athauda, S.B.P., Inoue, H., Iwamatsu, A., and Takahashi, K. 1998. Acid proteinase from Nepenthes distillatoria (Badura). Adv. Exp. Med. Biol. 436: 453-458.

Athauda, S.B.P., Inoue, H., Iwamatsu, A., and Takahashi, K. 2002. Purification and enzymatic characterization of an aspartic proteinase (Nepenthesin) from the insectivorous plant Nepenthes distillatoria. Proc. 4th Interntl. Carnivor. Plant Conf. Tokyo, 117-124.

Athauda, S.B.P., Matsumoto, K., Rajapakshe, S., Kuribayashi, M., Kojima, M., Kubomura-Yoshida, N., Iwamatsu, A., Shibata, C., Inoue, H., and Takahashi, K. 2004. Enzymic and structural characterization of nepenthesin, a unique member of a novel subfamily of aspartic proteinases. Biochem. J. 380: 295-306.

Athauda, S.B.P., Tanji, M., Kageyama, T., and Takahashi, K. 1989. A comparative study on the $\mathrm{NH}_{2}$-terminal amino acid sequences and some other properties of six isozymic forms of human pepsinogens and pepsins. J. Biochem. 106: 920-927.

Chandler, G.E., and Anderson, J.W. 1976. Studies on the origin of some hydrolytic enzymes associated with the leaves and tentacles of Drosera species and their role in heterotrophic nutrition. New Phytol. 77: 51-62.

Clancy, F.G.A., and Coffey, M.D. 1977. Acid phosphatase and protease release by the insectivorous plant Drosera rotundifolia. Can. J. Bot. 56: 480-488.

Fujinaga, M., Cherney, M.M., Oyama, H., Oda, K., and James, M.N.G. 2004. The molecular structure and catalytic mechanism of a novel carboxyl peptidase from Scytalidium lignicolum. Proc. Natl. Acad. Sci. USA 101: 3364-3369.

Furihata, C., Kawachi, T., and Sugimura, T. 1972. Premature induction of pepsinogen in developing rat gastric mucosa by hormones. Biochem. Biophys. Res. Commun. 47: 705-711.

Huang, X.-P., Kagami, N., Inoue, H., Kojima, M., Kimura, T., Makabe, O., Suzuki, K., and Takahashi, K.. 2000. Identification of a glutamic acid and an aspartic acid residue essential for catalytic activity of aspergillopepsin II, a non-pepsin type acid proteinase. J.. Biol. Chem. 275: 26607-26614.

Juniper, B.E., Robins, R.J., and Joel, D.M. (eds.) 1989. The Carnivorous Plants. Academic Press, London.

Kataoka, Y., Takada, K., Oyama, H., Tsunemi, M., James, M.N., and Oda, K. 2005. Catalytic residues and substrate specificity of scytalidoglutamic peptidase, the first member of the eqolisin in family (G1) of peptidases. FEBS Lett. 579: 2991-2994.

Lobareva, L.S., Rudenskaya, G.N., and Stepanov, V.M. 1973. Pepsin-like protease from the insectivorous plant Nepenthes. Biokhimiya 38: 640-642.

Lüttge, U. 1964. Untersuchungen zur Physiologie der Carnivoren-Drüsen. I. Mitteilung die an den verdauungsvorgängen beteiligten enzyme. Planta 63: 103-117.

Nishii, W., Maruyama, T., Matsuoka, R., Muramatsu, T., and Takahashi, K. 2002. The unique sites in SulA protein preferentially cleaved by ATP-dependent Lon protease from Escherichia coli. Eur. J. Biochem. 269: 451-457.

Nishii, W., Ueki, T., Miyashita, R., Kojima, M., Kim, Y-T., Sasaki, N., Murakami-Murofushi, K., and Takahashi, K. 2003a. Structural and enzymatic characterization of physarolisin (formerly physaropepsin) proves that it is a unique serine-carboxyl proteinase. Biochem. Biophys. Res. Commun. 301:1023-1029. 
Nishii, W., Kuriyama, H., and Takahashi, K. 2003b. The Physarum polycephalum php gene encodes a unique cold-adapted serine-carboxyl peptidase, physarolisin II. FEBS Lett. 546: 340-344.

Robins, R.J., and Juniper, B.E. 1980. The secretory cycle of Dionaea muscipula Ellis. IV. The enzymology of the secretion. New Phytol. 86: 401-412.

Sasaki, H., Nakagawa, A., Muramatsu, T., Suganuma, M., Sawano, Y., Kojima, M., Kubota, K., Takahashi, K., and Tanokura, M. 2004. The three-dimensional structure of aspergilloglutamic peptidase from Aspergillus niger. Proc. Japan Acad. 80: Ser. B. 435-438.

Scala, J., Iott, K., Schwab, D.W., and Semersky, F.E. 1969. Digestive secretion of Dionaea muscipula (Venus's flytrap). Plant Physiol. 44: 367-371.

Takahashi, K., Athauda, S.B.P., Matsumoto, K., Rajapakshe, S., Kuribayashi, M., Kojima, M., KubomuraYoshida, N., Iwamatsu, A., Shibata, C., and Inoue, H. 2005. Nepenthesin, a unique member of a novel subfamily of aspartic proteinases: enzymatic and structural characteristics. Curr. Protein Pept. Sci. 6: 513-525.

Takahashi, K., Chang, W.-J., and Ko, J.-S. 1974. Specific inhibition of acid proteinases from brain, kidney, skeletal muscle, and insectivorous plants by diazoactyl-DL-norleucine methyl ester and by pepstatin. J. Biochem. 76: 897-899.

Tökés, Z.A., Woon, W.C., and Chambers, S.M. 1974. Digestive enzymes secreted by the carnivorous plant Nepenthes macfarlanei L. Planta 119: 39-46.

Wlodawer, A., Li, M., Dauter, Z., Gustchina, A, Uchida, K., Oyama, H., Dunn, B.M., and Oda, K. 2001. Carboxyl proteinase from Pseudomonas defines a novel family of subtilisin-like enzymes. Nat. Struct. Biol. 8: 442-446.

Woessner, J.F. 2004. Nepenthesin. In: Barrett, A.J., Rawlings, N.D., Woessner, J.F. (eds.) Handbook of Proteolytic Enzymes, 2nd Ed., Volume 1: pp. 85-86. Academic Press, New York.

Yabuki, Y., Kubota, K., Kojima, M., Inoue, H., and Takahashi, K. 2004. Identification of a glutamine residue essential for catalytic activity of aspergilloglutamic peptidase by site-directed mutagenesis. FEBS Lett. 569: 161-164.

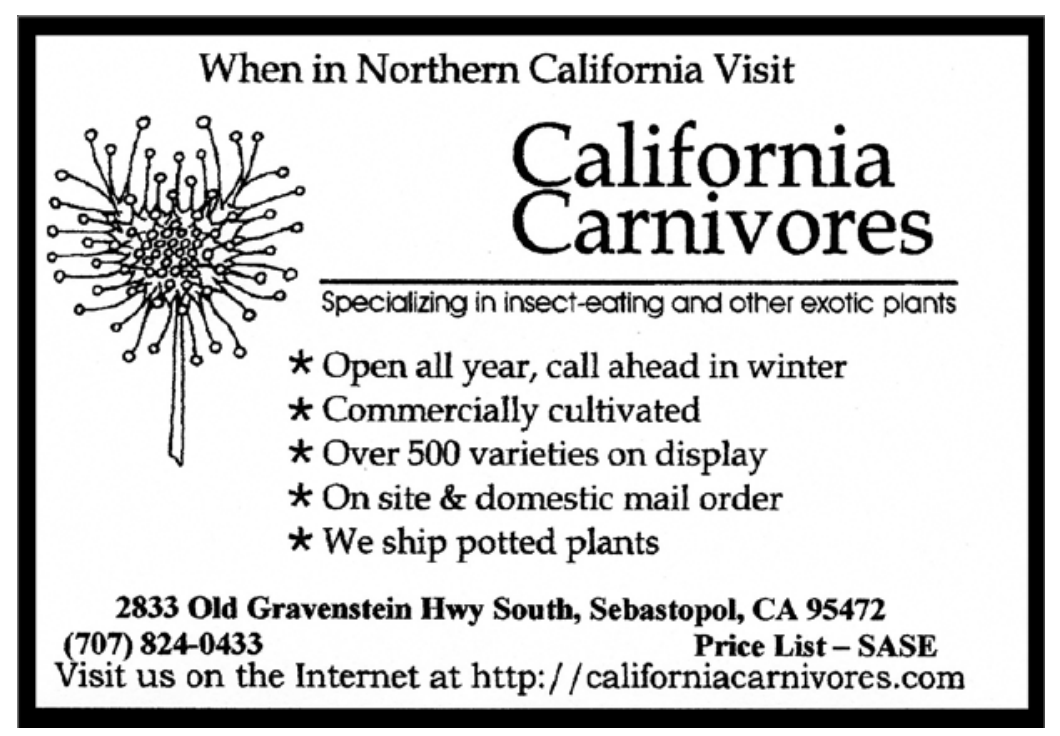

